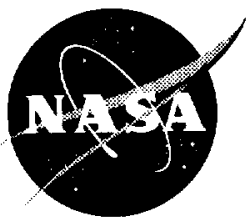

\title{
Design, Fabrication and Test of a High Efficiency Refractive Secondary Concentrator for Solar Applications
}

Wayne A. Wong and Steven M. Geng Glenn Research Center, Cleveland, Ohio

Charles H. Castle and Robert P. Macosko Analex Corporation, Brook Park, Ohio

Prepared for the 35th Intersociety Energy Conversion Engineering Conference sponsored by the American Institute of Aeronautics and Astronautics Las Vegas, Nevada, July 24-28, 2000

National Aeronautics and Space Administration

Glenn Research Center 


\section{Acknowledgments}

The authors would like to recognize the contributions to this effort by Donald Buchele, Donald Jaworske, Frank Madi, Daniel Sommerville, Michael Swiatek, and the GRC Tank 6 test support crew.

Available from

NASA Center for Aerospace Information 7121 Standard Drive

Hanover, MD 21076

Price Code: A03
National Technical Information Service 5285 Port Royal Road Springfield, VA 22100 Price Code: A03 


\title{
DESIGN, FABRICATION AND TEST OF A HIGH EFFICIENCY REFRACTIVE SECONDARY CONCENTRATOR FOR SOLAR APPLICATIONS
}

\author{
Wayne A. Wong and Steven M. Geng \\ National Aeronautics and Space Administration \\ Glenn Research Center \\ Cleveland, Ohio 44135 \\ Charles H. Castle and Robert P. Macosko \\ Analex Corporation \\ Brook Park, Ohio 44142
}

\begin{abstract}
Common to many of the space applications that utilize solar thermal energy such as electric power conversion, thermal propulsion, and furnaces, is a need for highly efficient, solar concentration systems. An effort is underway to develop the refractive secondary concentrator, which uses refraction and total internal reflection to efficiently concentrate and direct solar energy. When used in combination with advanced primary concentrators, the refractive secondary concentrator enables very high system concentration ratios $(10,000$ to 1$)$ and very high temperatures $(>2000 \mathrm{~K})$.

Presented is an overview of the effort at the NASA Glenn Research Center to evaluate the performance of a prototype single crystal sapphire refractive secondary concentrator and to compare the performance with analytical models. The effort involves the design and fabrication of a secondary concentrator, design and fabrication of a calorimeter and its support hardware, calibration of the calorimeter, testing of the secondary concentrator in NASA Glenn's Tank 6 solar thermal vacuum facility, and comparing the test results with predictions. Test results indicate an average throughput efficiency of $87 \%$. It is anticipated that reduction of a known reflection loss with an anti-reflective coating would result in a secondary concentrator throughput efficiency of approximately $93 \%$.
\end{abstract}

\section{INTRODUCTION}

Space solar thermal applications have been identified that will require efficient, light weight energy delivery systems that can enable the high temperatures required by these systems. Some of the proposed power and propulsion systems have temperature requirements in excess of $2000 \mathrm{~K}$. The infrared heat loss at these high temperatures is significant and small receiver apertures are required to minimize this loss. Consequently, the solar concentration ratio of the energy delivery system needs to be as high as 10,000 to 1 resulting in a need for very precise pointing and tracking systems. Light weight, thin film, deployable primary concentrators have been proposed for these systems. No primary

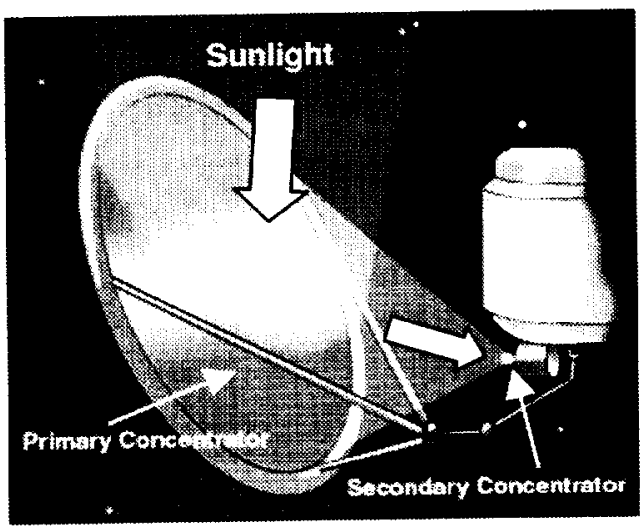

Figure 1 - Solar concentration system 
concentrator technology, rigid or inflatable, is capable of achieving the system requirements alone. The addition of a secondary concentrator to the energy delivery system enables the higher concentration ratios and relaxes the pointing and tracking requirements. Figure 1 conceptually shows a solar concentration system composed of a primary and a secondary concentrator, which provides concentrated energy to heat a receiver cavity.

The innovative high efficiency refractive secondary concentrator as shown in Figure 2, offers significant advantages over all other types of secondaries and is an enabling technology for ultra high temperature applications $(\sim 2000 \mathrm{~K}$ or higher). The refractive secondary offers the highest throughput efficiency, provides for flux tailoring, requires no active cooling, relaxes the pointing and tracking requirements of the primary concentrator, and enables very high system concentration ratios. The refractive secondary concentrator technology has broad applicability to any system that requires the conversion of solar energy to heat, including electric power generation, thermal propulsion and high temperature furnaces. It may also be advantageously used in low temperature applications to deliver sunlight to point of use such as a light pipe. Modeling has shown significant performance benefits of the refractive secondary as compared to the conventional hollow reflective secondary'.

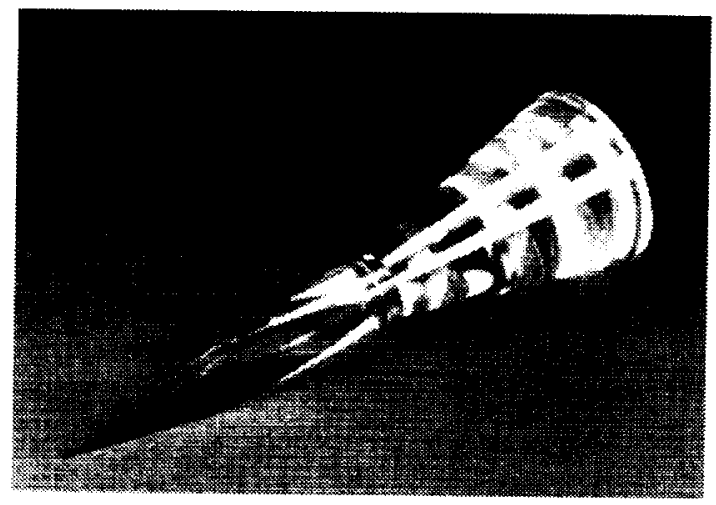

Figure 2 - Sapphire refractive secondary concentrator
The NASA Glenn Research Center (GRC) initiated development of the refractive secondary concentrator in support of NASA Marshall Space Flight Center's Shooting Star Project, a solar thermal propulsion flight experiment. Significant accomplishments in developing the refractive secondary concentrator for the Shooting Star Project include: developing optics and thermal design and analysis tools ${ }^{1,2.3}$, assessing the significant performance benefits of the refractive secondary via modeling ${ }^{1,3}$, fabricating a number of prototype secondaries, and performing materials characterization tests concluding in part that sapphire is a very attractive material for this application ${ }^{4}$. Other work includes benchtop evaluations of an acrylic refractive secondary using a helium neon laser as a source. These tests help to verify the ray trace models ${ }^{5}$, determined the efficiency of the acrylic demonstrator and concluded that the throughput efficiency is not appreciably affected by variations in the flux profile impinging on the secondary inlet surface ${ }^{6}$. Studies have also been conducted at GRC which show that a refractive secondary concentrator can be advantageously used as part of a solar Stirling power system for deep space applications?.

The Shooting Star Project was cancelled due to funding constraints in Fall 1998. The effort reported on here is in support of Space Solar Power, a project to develop orbiting solar power plants. The emphasis of this effort is to demonstrate the performance benefits of the refractive secondary concentrator through simulated on-sun vacuum testing.

\section{TEST OBJECTIVES}

The objectives of this effort are to design and fabricate a sapphire refractive secondary concentrator and determine the throughput efficiency of the secondary via solar vacuum testing in GRC's Tank 6 facility. Efficiency would be determined using a low temperature liquid cooled calorimeter. Further, for this test, no attempt was made to reduce the reflection loss at the front face of the refractive secondary concentrator with coatings. The test results would be compared to ray trace modeling predictions. 


\section{REFRACTIVE SECONDARY CONCENTRATOR}

The refractive secondary concentrator design was driven by: 1 . Suitability for testing in Tank 6 , particularly with respect to the nature of the concentrated solar spot from the primary concentrator, 2. Availability of high purity sapphire in sufficiently large size to allow fabrication of the refractive secondary concentrator and extractor tip as one continuous unit (previous zirconia prototypes were fabricated as two separate parts that were bonded together) and 3 . Representative size/geometry for a variety of solar thermal applications that would allow follow on uses for the unit.

The design parameters for the sapphire secondary concentrator were determined by first considering the performance of the existing Tank 6 primary concentrator which is about $15 \mathrm{ft}$ in diameter and produces a 7 inch spot diameter at it's focus. It was determined that the largest piece of single crystal sapphire available at the time would support an inlet aperture of about 3.5 inches. It was then determined that typical primary concentrator systems tend to optimize near a diameter to focal length ratio that produces a light beam that subtends a 60 degree included angle (30 degree half angle).

To maximize the usefulness of the sapphire refractive secondary concentrator in an actual solar thermal system it was decided to design the secondary for an acceptance half angle of 27 degrees. This angle was determined by placing the secondary concentrator inlet aperture at the primary concentrator focal plane and projecting back from the aperture edge to the extremities of the primary concentrator assuming that the outer set of facets were removed (this is discussed further in a later section).

Having determined the inlet aperture size and acceptance angle, the secondary concentrator was then designed to maximize the throughput energy with a 3 sided extractor tip.

A 4 inch $\times 4$ inch $\times 11.7$ inch sapphire bar was acquired from Crystal Systems Inc., Salem, MA, and delivered to Computer Optics Inc., Hudson, $\mathrm{NH}$, for machining and polishing. Photos of the

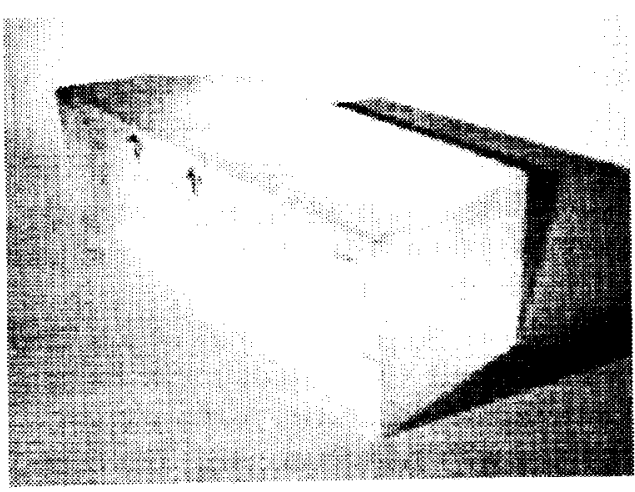

Figure 3 - Sapphire bar used to fabricate the refractive secondary concentrator

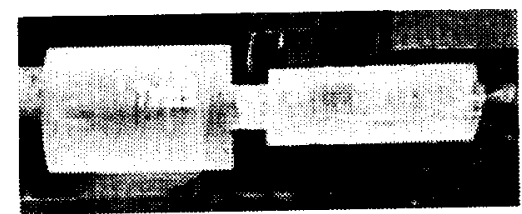

Figure 4 - Sapphire bar during fabrication

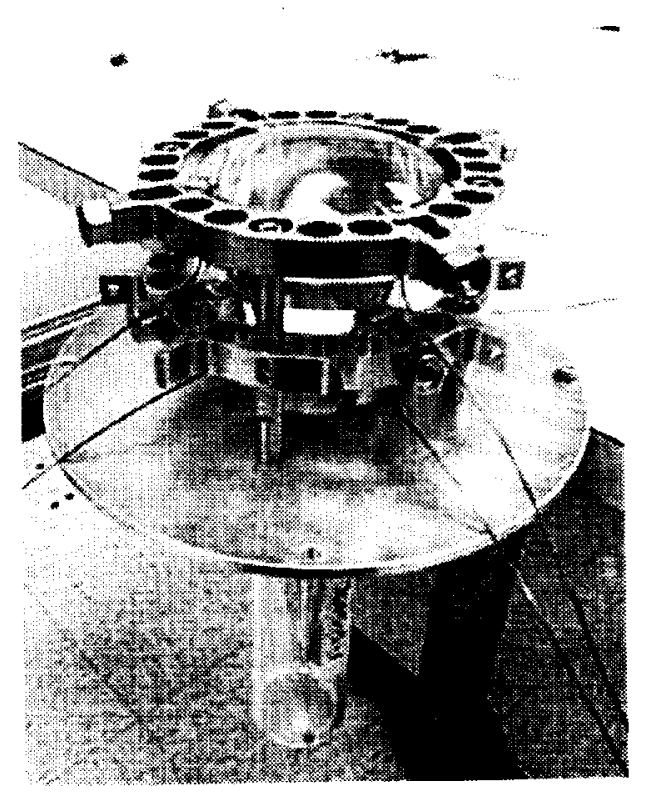

Figure 5 - Secondary concentrator installed in support structure

sapphire bar before and during machining are in Figures 3 and 4 . The finished refractive secondary concentrator, shown in Figures 2 and 5 , measures 3.5 inch diameter and 11.2 inch overall length. 
A prototype secondary concentrator holder designed for The Shooting Star Project was then modified to accept the sapphire refractive secondary concentrator. Figure 5 shows the secondary concentrator mounted in its holder. The secondary concentrator is supported using a support ring at the inlet surface and one around the center of gravity using 8 small spring loaded silver plated shoes. The shoes minimize contact with the refractive secondary and are each instrumented with thermocouples. The support structure was designed with flight requirements in mind. The shoes minimize conduction losses, are compliant to thermal expansion, and do not interfere with total internal reflection at the contact points.

\section{RAY TRACE MODELING}

The completed sapphire refractive secondary concentrator was inspected at NASA GRC in order to determine the as-built geometry. All dimensions were found to be within acceptable tolerances. A ray trace model was then constructed with OptiCAD using the as-built dimensions. Figure 6 shows a representative ray trace through the secondary concentrator model along with the resulting axial flux profile from the secondary on to the receiver wall. The ray trace analysis, which does not include a reflection loss at the front face of the refractive secondary concentrator predicts a throughput efficiency of $98 \%$. Applying a reflection loss of $8 \%$ results in an efficiency of $90 \%$. It is anticipated that an anti-reflective coating would reduce this loss resulting in an efficiency of $96 \%$.

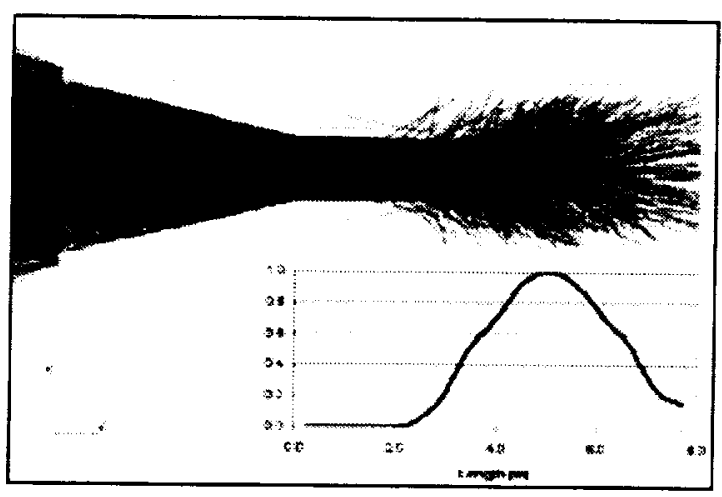

Figure 6 - Ray trace model predicts the flux distribution on the receiver wall

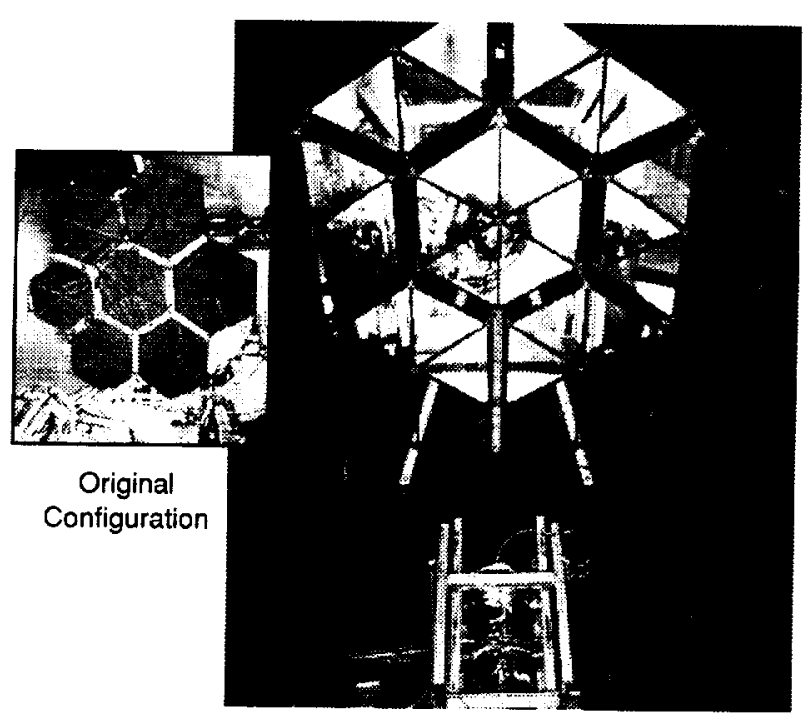

Figure 7 - Tank 6 concentrator in original configuration (left) and secondary concentrator test configuration with calorimter (right)

\section{FACILITY AND HARDWARE}

Tank 6 Solar Vacuum Facility

GRC's Tank 6 Thermal Vacuum facility is 25 feet in diameter and 60 feet long and features a solar simulator that is capable of providing 1.2 suns at the 15 feet diameter primary concentrator ${ }^{8}$. A radiometer mounted to the primary concentrator is used to measure the solar flux intensity. The facility has 12 cryopumps that can provide vacuum levels less than $1 \times 10^{-6}$ torr and liquid Nitrogen cold walls to simulate the thermal environment in space.

Due to budget and schedule constraints, changes to the existing solar simulator and concentrator set-up were kept to a minimum. In order to provide an entrance half angle to the secondary concentrator within 30 degrees, typical of a system application, the outer 18 facets of the primary concentrator were removed from the hex paneis of the primary concentrator as shown in Figure 7 , leaving the inner 24 facets. This reduced the entrance half angle to 27 degrees for a 3.5 inch aperture at the focal plane. The spot from the primary concentrator is approximately 7 inches in diameter. However for simplicity, no attempt was 
made to re-align the primary concentrator facets to provide a smaller focal spot. Spillage of light outside of the 3.5 inch secondary concentrator diameter would not enter the calorimeter and would not be measured.

\section{Calorimeter}

The calorimeter used for the experiment was one that was previously constructed and used in Tank 6 . The calorimeter is a copper cylinder with copper coolant tubing surrounding and soldered to the outer diameter and bottom of the cylinder. A copper plate with associated coolant tubing is attached to the inlet face of the calorimeter. An opening in this allows the entry of the solar energy. The inside surfaces of the calorimeter were coated with a vacuum rated high emissivity black paint. The calorimeter was cooled with a $40 / 60 \mathrm{mix}$ by volume of ethylene glycol and water. A water cooled silvered splash shield in front of the calorimeter was used to reject the energy in the approximately 7 inch spot that lay outside the 3.5 inch aperture diameter. The splash shield installed in front of the calorimeter is shown in Figure 8 prior to insulation.

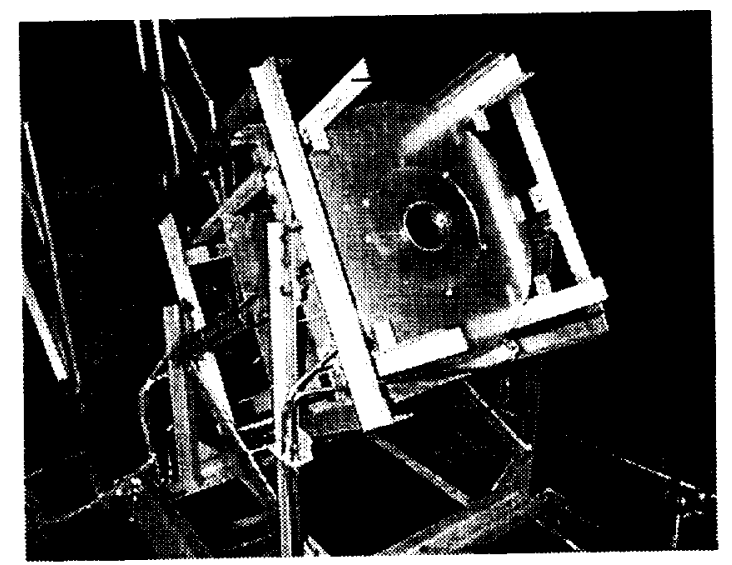

Figure 8 - Test assembly showing the splash shield in front of calorimeter

Three immersion thermocouples were installed at the coolant inlet and outlet points of the calorimeter. A high accuracy piston flow meter was used in the coolant loop to measure flow rate.
This type of flow meter required that a glycol/water mixture be used instead of water. The specific gravity of the coolant was determined using volumetric/weight measurements of the mix. The specific heat of the mixture was obtained from data published in the 1997 ASHRAE Fundamentals Handbook. The coolant was supplied to the calorimeter via a recirculating chiller that maintained a constant flow and supply temperature. The total energy input to the calorimeter was calculated then corrected for calorimeter losses using:

$$
Q=m c_{p}\left(T_{\text {in }}-T_{\text {out }}\right)
$$

where:

$$
\begin{aligned}
& Q=\text { energy input } \\
& m=\text { coolant mass flowrate } \\
& C_{p}=\text { specific heat of coolant at }\left(T_{\text {in }}-T_{\text {out }}\right) / 2 \\
& T_{\text {in }}=\text { coolant inlet temp. (average of } 3 \\
& \text { thermocouples) } \\
& T_{\text {out }}=\text { coolant outlet temp. (average of } 3 \\
& \text { thermocouples) }
\end{aligned}
$$

The calorimeter was insulated with aluminized mylar multi layer insulation (MLI). The calorimeter was operated at low temperature $\left(<150^{\circ} \mathrm{F}\right)$ and in vacuum, thus radiation and conduction heat loss from the calorimeter was minimized.

Quartz Heaters for Calorimeter Calibration Four 6000 watt quartz heaters, operated at low power, were installed in the calorimeter cavity to provide heat during the calibration of the calorimeter. The heater assembly was suspended with wires in the calorimeter as shown in Figure 9. The heaters provided a low mass, fast response heat source that simulated the energy input provided by the Tank 6 solar simulator. The heater electrical power was determined using voltage sense leads located near the heaters rather than at the power supply in order to minimize errors due to voltage drop through the power lines.

\section{TESTING AND RESULTS}

In order to assess the performance of the refractive secondary concentrator, three distinct tests were needed, each requiring a change in 


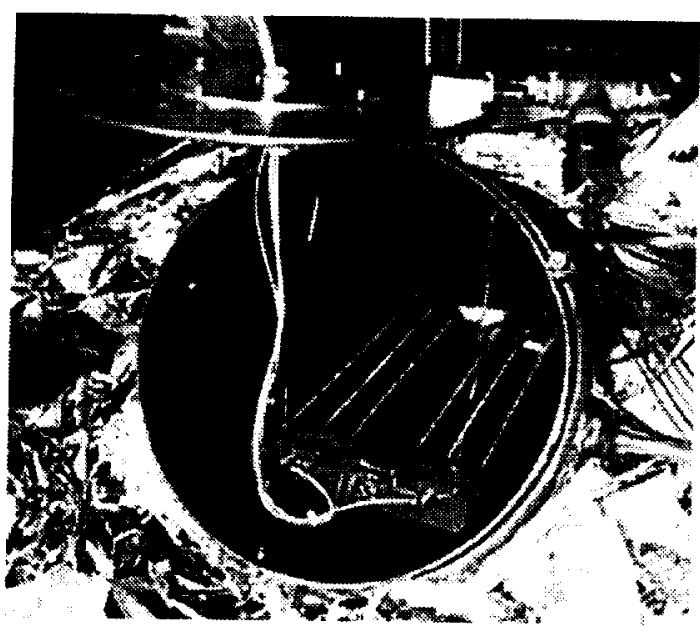

Figure 9 - Quartz calibration heaters installed inside the calorimeter

hardware and a pump down of the test facility to vacuum conditions: 1 . Calibration of the calorimeter, 2. Determination of baseline input power from the primary concentrator to the 3.5 inch aperture, and 3. Evaluation of efficiency of the refractive secondary concentrator. These tests were run with only 4 cryopumps for cost savings, providing approximately $2 \times 10^{-6}$ torr, and without the use of the coldwalls.

\section{Test 1 - Calorimeter Calibration}

The objective of Test 1 was to calibrate the calorimeter and determine its accuracy. This was done by using 4 quartz heaters to provide heat input to the calorimeter rather than light from the solar simulator. The level of agreement between electrical power into the heaters and power measured by the calorimeter gives an estimate of the accuracy of the calorimeter. For this test the calorimeter was completely insulated with multilayer foil insulation. The only potentially significant heat loss would be through the insulated mounting points by which the calorimeter was suspended. To assess this loss, the heaters were adjusted such that the calorimeter body reached equilibrium temperature with no flow through the calorimeter. At this point, the power into the heaters equals the loss through the insulated mounting points. Although this conduction loss was found to be small $(7 \mathrm{~W}$ conduction loss at calorimeter temperature of approximately $140^{\circ} \mathrm{F}$ ) it was included in the calculation to determine the power out of the calorimeter $\left(Q_{\text {calorimeter }}=Q_{\text {fluid }}+Q_{\text {conduction }}\right)$.

The calorimeter calibration test was performed with the quartz heater input power ranging between $1.0 \mathrm{~kW}$ to $5.9 \mathrm{~kW}$. Within this range the energy balance comparing the calculated power out of the calorimeter and the electrical power into the quartz heaters ranged between -0.2 to 1.2 percent. These results verified that the accuracy of the calorimeter was acceptable.

\section{Test 2 - Baseline Power}

The objective of Test 2 was to define repeatable system set points (number of solar simulator lamps used, solar simulator lamp power, and calorimeter flow rate) and to measure the baseline power into the 3.5 inch aperture at these points. Measuring the concentrated solar energy into the open aperture without the refractive secondary concentrator installed at these points establishes baseline power for comparison to results with the secondary concentrator in place to determine efficiency. Figure 10 is a photo of the water cooled splash shield and test aperture without the secondary concentrator installed. Visible are two sets of flux rakes located at the top and bottom of the splash shield used to monitor the relative intensity within the 7 inch spot diameter.

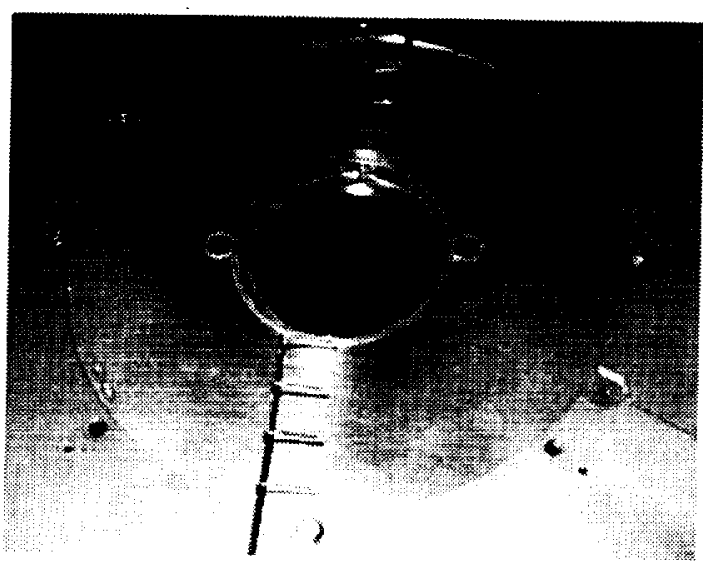

Figure 10 - Water cooled silver plated splash shield used to reject energy outside of the 3.5 inch aperture 


\section{Test 3 - Refractive Secondary Concentrator}

The objective of Test 3 was to measure the power through the refractive secondary concentrator at specific system set points, and by comparison with baseline power results from Test 2 , determine the throughput efficiency of the refractive secondary. Figure 11 is a photograph of the front of the refractive secondary concentrator installed in the splash shield/calorimeter assembly.

During the course of the experiment a number of issues arose regarding the solar simulator. As a result, and due to budgetary constraints and facility schedule, only three of the nine solar simulator lamps were used for this series of tests. Five system set points using these three lamps in different combinations and power levels define the test matrix. Table 1 identifies the system set points and the resulting baseline power into the open aperture ranging between 407 and 1,235 watts in Test 2. The throughput power of the refractive secondary concentrator in Test 3 , the resulting efficiency, and the efficiency with an antireflective coating on the inlet surface is also listed. Tests on sapphire wafers cut from the same parent material as the secondary and with a similar polish show that the reflectivity is about $8 \%$. Anti-reflective coatings have been identified that reduce the reflection loss to approximately $2 \%$. Applying such a coating on the front face of the refractive secondary concentrator is expected to result in a $6 \%$ efficiency gain or an average throughput efficiency of approximately $93 \%$.

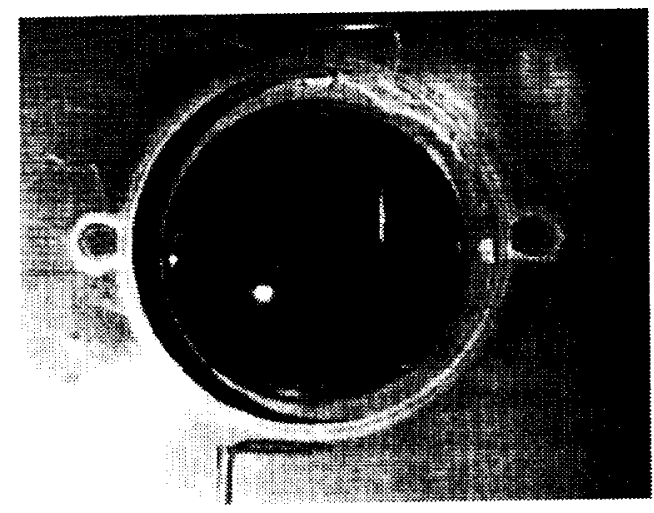

Figure 11 - Refractive secondary concentrator installed in the splash shield / calorimeter assembly

\section{ERROR ANALYSIS AND DISCUSSION}

The critical calculation of heat absorbed by the calorimeter $(\mathrm{Q})$ was based on the product of several measurements. The errors associated with each of these measurements contribute to the total probable error that is related to the calculation. The calculation of the refractive secondary concentrator (RSC) efficiency $(\eta)$ is even more sensitive to the individual measurement errors since it is calculated based on the quotient of two $Q$ calculations (heat absorbed by the calorimeter with the RSC installed divided by heat absorbed by the calorimeter without the RSC installed).

\begin{tabular}{|l|c|c|c|c|}
\hline $\begin{array}{c}\text { Solar Simulator Lamps } \\
\text { and Lamp Power } \\
\text { Setpoints }\end{array}$ & $\begin{array}{c}\mathrm{Q}_{\text {baseline }} \\
\text { (watts) }\end{array}$ & $\begin{array}{c}\mathrm{Q}_{\mathrm{RSC}} \\
\text { (watts) }\end{array}$ & $\begin{array}{c}\text { Efficiency } \\
(\%)\end{array}$ & $\begin{array}{c}\text { Estimated } \\
\text { Efficiency w/ } \\
\text { Anti-reflective } \\
\text { coating (\%) }\end{array}$ \\
\hline $\begin{array}{l}\text { Lamp 5 } \\
@ 20 \mathrm{~kW}\end{array}$ & 407 & 350 & $85 \%$ & $91 \%$ \\
\hline $\begin{array}{l}\text { Lamp 5 \& Lamp 6 } \\
@ 20 \mathrm{~kW} \mathrm{each}\end{array}$ & 703 & 611 & $86 \%$ & $92 \%$ \\
\hline $\begin{array}{l}\text { Lamp 3, Lamp 5 \& } \\
\text { Lamp 6 @ 20 kW each }\end{array}$ & 743 & 870 & $87 \%$ & $93 \%$ \\
\hline $\begin{array}{l}\text { Lamp 3 \& Lamp 6 } \\
@ 27 \mathrm{~kW} \mathrm{each}\end{array}$ & 1,235 & 1,080 & $87 \%$ & $96 \%$ \\
\hline $\begin{array}{l}\text { Lamp 3, Lamp 5 \& } \\
\text { Lamp 6 @ 27 kW each }\end{array}$ & & 666 & $90 \%$ & $93 \%$ \\
\hline
\end{tabular}

Table 1 - Test point settings and results indicating an average efficiency of $87 \%$ and an average efficiency with an anti-reflective coating of $93 \%$ 
With proper technique, measurement errors can be kept to a minimum. The test data taken to determine the RSC efficiency was taken at steadystate conditions. Therefore, it was possible to take an average of data over 5 minutes with each measurement taken every 10 seconds. This technique was used to minimize the random errors. All thermocouples were calibrated in place to eliminate errors associated with the long cables that were required to connect the thermocouples with the data system. The critical temperature measurements of the $\mathrm{H}_{2} \mathrm{O}$ /Glycol mixture that were used in the calculation of $Q$ were actually the average of several thermocouples.

Sample calculations of the estimated probable errors associated with $Q$ and $\eta$ are shown below:

\section{Calculation 1}

Heat absorbed by the calorimeter test rig (Q)

$Q=\rho C p F \Delta T$

where

$\rho$ density of $\mathrm{H}_{2} \mathrm{O} / \mathrm{Glycol}$ mixture $\left(\mathrm{lb} / \mathrm{ft}^{3}\right)$

Cp Specific Heat of $\mathrm{H}_{2} \mathrm{O}$ /Glycol mixture (BTU//bº

F Volumetric Flow Rate of $\mathrm{H}_{2} \mathrm{O} / \mathrm{Glycol}$ mixture $\left(\mathrm{ft}^{3} / \mathrm{hr}\right)$

$\Delta T$ Temperature Rise in $\mathrm{H}_{2} \mathrm{O}$ /Glycol mixture through calorimeter $\left({ }^{\circ} \mathrm{F}\right)$

$$
\begin{aligned}
\text { Error }= & {\left[\left(\rho_{\text {orr }} / \rho\right)^{2}+\left(C p_{\text {orr }} / C p\right)^{2}+\left(F_{\text {err }} / F\right)^{2}+\left(T_{\text {orr }} / T\right)^{2}+\right.} \\
& \left.\left(T_{\text {orr }} / T\right)^{2}\right]^{1 / 2} \\
\text { Error }= & {\left[(0)^{2}+(0.008 / 0.806)^{2}+(0.00877 / 1.753)^{2}+\right.} \\
& \left.(1.0 / 72.5)^{2}+(1.0 / 117.4)^{2}\right]^{1 / 2} \\
\text { Error }= & \pm 1.7 \% \quad(Q=1235 \mathrm{~W} \pm 22 W)
\end{aligned}
$$

Calculation 2

Efficiency of the RSC

$\eta=Q_{\text {RSC }} / Q_{\text {BASELINE }}$

where

$$
\begin{array}{ll}
Q_{\text {RSC }} & \text { Heat into the calorimeter with } \\
& \text { RSC installed (W) } \\
Q_{\text {BASELINE }} & \text { Heat into the calorimeter without } \\
& \text { RSC (W) }
\end{array}
$$

$$
\begin{aligned}
& \text { Error }=\left[\left(Q_{\mathrm{RSCOr}^{\prime}} / \mathrm{Q}_{\mathrm{RSC}}\right)^{2}+\left(\mathrm{Q}_{\mathrm{BASELINEOr}} / \mathrm{Q}_{\text {BASELINE }}\right)^{2}\right]^{1 / 2} \\
& \text { Error }=\left[(18.4 / 1080)^{2}+(21.0 / 1235)^{2}\right]^{1 / 2} \\
& \text { Error }= \pm 2.4 \% \quad(\eta=87.3 \% \pm 2.1 \%)
\end{aligned}
$$

\section{CONCLUDING REMARKS}

The refractive secondary concentrator was successfully fabricated out of a bar of single crystal sapphire. Vacuum testing of the secondary concentrator using Tank 6's solar simulator and comparing the results with baseline power tests into the calorimeter aperture reveal that the throughput efficiency ranged between $85-90 \%$. It is anticipated that the reflection loss at the inlet of the secondary concentrator can be reduced with an anti-reflective coating resulting in throughput efficiency of about $93 \%$.

Results from the ray trace analysis indicates that with an anti-reflective coating, the throughput efficiency is $96 \%$. Assuming the application of the coating, the test results and the modeling results are within $3 \%$ agreement. The error analysis may partially account for the difference, however other factors may also be considered. Testing on sapphire specimens up to 1 inch thick show no discernable absorption. Absorption can not be discounted however as the optical path through the refractive secondary is much greater than the specimens especially considering the multiple reflections that the light undergoes. In addition, the reflection loss may be higher than assumed due to the radial nature of the inlet surface as oppose to the flat wafers that were used to determine reflectivity. Lastly, while utmost care was used in setting up the hardware, alignment error may have contributed to the divergence.

Nevertheless, this test successfully demonstrates the high efficiency potential of the refractive secondary concentrator. Potential future activities to further develop the technology include high temperature, high power throughput tests, antireflective coating tests, Infrared loss test, Infrared retainment coatings development, and additional material characterization and interaction tests. 


\section{REFERENCES}

1. W.A. Wong, R.P. Macosko, "Refractive Secondary Concentrators for Solar Thermal Applications" NASA Glenn Research Center, TM 1999-209379, IECEC-99-01-2678, Vancouver, British Columbia, August 1999.

2. S.M. Geng, R.P. Macosko, "Transient Thermal Analysis of Refractive Secondary Solar Concentrator" NASA Glenn Research Center, TM 1999-209384, IECEC 99-01-2690, Vancouver, British Columbia, August 1999.

3. J.A. Soules, D.R. Buchele, C.H. Castle, R.P. Macosko, "Design and Fabrication of a Dielectric Total Internal Reflecting Solar Concentrator and Associated Flux Extractor for Extreme High Temperature (2500 K) Applications" NASA Lewis Research Center, CR204145, November 1997.

4. D. Zhu, N.S. Jacobson, R.A. Miller, "Thermal Mechanical Stability of Single Crystal Oxide Refractive Concentrators for High-
Temperature Solar Thermal Propulsion" NASA Glenn Research Center, TM 1999208899, February 1999.

5. D.A. Jaworske, W.A. Wong, T.J. Skowronski, "Optical Evaluation of a Refractive Secondary Concentrator" NASA Glenn Research Center, IECEC 99-01-2679, Vancouver, British

Columbia, August 1999.

6. D.A. Jaworske, T.J. Skowronski, "Optical Efficiency of a Refractive Secondary Concentrator" NASA Glenn Research Center, AlAA-2000-2994, Las Vegas, Nevada, July 2000.

7. L.S. Mason, "Solar Stirling for Deep Space Applications" NASA Glenn Research Center, TM 1999-209656, December 1999.

8. R.K. Shaltens, R.V. Boyle, "Initial Results From the Solar Dynamic (SD) Ground Test Demonstration (GTD) Project at NASA Lewis" NASA Lewis Research Center, TM 107004, IECEC 95-421, Orlando, Florida, August 1995. 
Public reporting burden for this collection of information is estimated to average 1 hour per response, including the time tor reviewing instructions. searching existing data sources. collection of information, including suggestions for reducing this burden, to washingtion of information. Send comments regarding this burden estimate or any other aspect of this Davis Highway. Suite 1204. Arlington. VA 22202-4302, and to the Otfice of Management and Budget, Papenort Reduction Project (0704-0180), Washions and Reports, 1215 Jefferson

1. AGENCY USE ONLY (Leave blank)

4. TITLE AND SUBTITLE

July 2000

Technical Memorandum

Design, Fabrication and Test of a High Efficiency Refractive

Secondary Concentrator for Solar Applications

6. AUTHOR(S)

WU-632-81-0A-00

Wayne A. Wong, Steven M. Geng, Charles H. Castle, and Robert P. Macosko

7. PERFORMING ORGANIZATION NAME(S) AND ADDRESS(ES)

National Aeronautics and Space Administration

John H. Glenn Research Center at Lewis Field

Cleveland, Ohio 44135-3191

5. FUNDING NUMBERS

CPONSORINGMONITORING AGENCY MAME(S) AND ADDAESS(ES)

9. SPONSORINGMONITORING AGENCY NAME(S) AND ADDRESS(ES)

10. SPONSORINGMONITORING AGENCY REPORT NUMBER

National Aeronautics and Space Administration

Washington. DC 20546-0001

NASA TM-2000-210339

AIAA-2000-2998

\section{SUPPLEMENTARY NOTES}

Prepared for the 35th Intersociety Energy Conversion Engineering Conference sponsored by the American Institute of Aeronautics and Astronautics, Las Vegas, Nevada, July 24-28, 2000. Wayne A. Wong and Steven M. Geng, NASA Glenn Research Center; Charles H. Castle and Robert P. Macosko, Analex Corporation, 3001 Aerospace Parkway, Brook Park, Ohio 44142. Responsible person, Wayne A. Wong, organization code 5490, (216) 433-6318.

12a. DISTRIBUTIONVAVAILABILITY STATEMENT

Unclassified - Unlimited

Subject Category: 20

Distribution: Nonstandard

This publication is available from the NASA Center for AeroSpace Information, (301) 621-0390.

13. ABSTRACT (Maximum 200 words)

Common to many of the space applications that utilize solar thermal energy such as electric power conversion, thermal propulsion, and furnaces, is a need for highly efficient, solar concentration systems. An effort is underway to develop the refractive secondary concentrator, which uses refraction and total internal reflection to efficiently concentrate and direct solar energy. When used in combination with advanced primary concentrators, the refractive secondary concentrator enables very high system concentration ratios $(10,000$ to 1$)$ and very high temperatures $(>2000 \mathrm{~K})$. Presented is an overview of the effort at the NASA Glenn Research Center to evaluate the performance of a prototype single crystal sapphire refractive secondary concentrator and to compare the performance with analytical models. The effort involves the design and fabrication of a secondary concentrator, design and fabrication of a calorimeter and its support hardware, calibration of the calorimeter, testing of the secondary concentrator in NASA Glenn's Tank 6 solar thermal vacuum facility, and comparing the test results with predictions. Test results indicate an average throughput efficiency of 87 percent. It is anticipated that reduction of a known reflection loss with an anti-reflective coating would result in a secondary concentrator throughput efficiency of approximately 93 percent.

14. SUBJECT TERMS

Secondary concentrators; Solar concentrators; Solar collectors;

Solar energy; Solar power generation; Solar propulsion; Solar furnaces

\begin{tabular}{|c|c|}
\hline $\begin{array}{c}\text { 17. SECURITY CLASSIFICATION } \\
\text { OF REPORT }\end{array}$ & $\begin{array}{c}\text { 18. SECURITY CLASSIFICATION } \\
\text { OF THIS PAGE } \\
\text { Unclassified }\end{array}$ \\
Unclassified
\end{tabular}

19. SECURITY CLASSIFICATION OF ABSTRACT Unclassified
15. NUMBER OF PAGES 15 16. PRICE CODE $\mathrm{A} 03$

20. LIMITATION OF ABSTRACT Standard Form 298 (Rev. 2-89) Prescribed by ANSI Std. Z39-18 298-102 



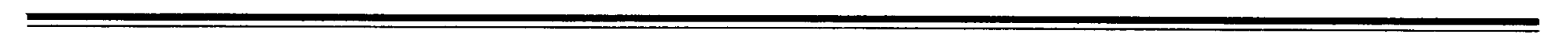

